supposed to form on the $\alpha$-atom, there are then seven cases of agreement with the hypothesis of parallelism, eight disagreements and nine remaining doubtful. If the ring forms on the $\beta$-carbon there are then ten cases of agreement and ten of disagreement and four in doubt. If the ring forms on the $\delta$-carbon there result six agreements, twelve disagreements and six doubtful. But it has been seen that if the ring forms on the $\gamma$-carbon there are twenty-four agreements, no disagreements and none in doubt. As the chances that an event which can happen in two equally probable ways will happen in exactly the same way twenty-four times out of twenty-four trials is only one in seventeen million it seems certain that the lactonic ring in these monobasic sugar lactones forms on the $\gamma$-carbon atom.

[CONTRIBUTTON FROM THE WELLCOME CHEMICAL RESEARCH LABORATORIES, LONDON.]

\title{
CHEMICAL EXAMINATION OF PUMPKIN SEED.
}

BY FREDERICR B, POWER AND ARTHCR H. SALWAY.

Received January I3, 1910.

The seeds of the common pumpkin (Cucurbita pepo, Linné) have been recognized for several decades by the United States Pharmacopoeia under the title of Pepo, and are regarded as an efficient and harmless taenifuge. This property appears to have been generally attributed to the fatty oil contained in the seed, which is stated to have been used with success in repeated half-ounce doses. ${ }^{1}$ On the other hand, Heckel ${ }^{2}$ found that the membrane surrounding the embryo is capable of expelling tapeworms, and as the membrane contains a resin, he believed this to be the active constituent. There is, however, no indication that Heckel had in any way confirmed this supposition by the separate administration of the resin. A more definite observation regarding the activity of the resin appears to have been made by Wolfi, since it is recorded $^{3}$ that he found this efficient as a taenifuge in doses of $15 \mathrm{grams}$, whereas the fatty oil, when pure and tree trom resin, was inert. Ordinarily, however, the remedy is employed in the form of the kernels of the fresh seed, suitably prepared, in doses ranging from 30 to 200 grams.

No complete chemical examination has hitherto been made of pumpkin seeds, and the constituents of their fatty oil have been only imperfectly known. The results of an investigation by Kopylow, ${ }^{4}$ in 1876 , showed that previous statements respecting the presence of an alkaloid or glicoside in these seeds could not be confirmed, but that they contained, be-

${ }^{1}$ Lancet, Sept. 25, 1875, p. 462.

2 Ibid. and Pharm. J., Oct., 1875, p. 308. Compare also Vigieo, Amer. J. Pharm., 1876, p. 509 .

${ }^{3} U$. S. Dispensatory, I8th Edit., p. Ior2.

- Pharm. Zeit. für Russland, 1876, p. 5 r3. 
sides fatty oil, some sugar and a soft resin. The expressed oil was stated to consist of the glycerides of palmitic, myristic, and oleic acids, while the oil extracted from the press-cake by means of ether also contained these acids in a free state. Lewkowitsch ${ }^{1}$ describes pumpkin seed oil, and records its physical and chemical constants, as also some of the constants of the mixed fatty acids obtained from the oil, but makes no statement concerning its composition.

In view of the medicinal use of pumpkin seeds, and the deficiency of knowledge respecting their constituents, it seemed desirable to subject them to a complete examination. It was also thought possible that thereby, in conjunction with physiological tests, some further and more definite information might be obtained as to the character of the constituent upon which their reputed action as a taenifuge depends. The results of the present investigation, together with the conclusions drawn therefrom, are summarized at the end of this paper.

\section{EXPERIMENTAL.}

The material employed was obtained from the United States, and consisted of fresh pumpkin seeds, which corresponded in all respects to the description given of them in the United States Pharmacopoeia.

A portion of the crushed seed was first tested for the presence of an alkaloid by means of Prollius' fluid, but with a negative result.

For the purpose of a complete examination, 22.5 kilograms of the seed were crushed and the shells separated as completely as possible from the kernels. The shells amounted to 4.68 kilograms, thus corresponding to 20.8 per cent. of the weight of the seed. The ground kernels were then subjected to strong hydraulic pressure, when 4350 grams of fatty oil were obtained, corresponding to 19.3 per cent. of the weight of the entire seed. The so-called "press-cake" remaining after the removal of the oil amounted to 12.7 kilograms. These operations connected with the expression of the oil were carefully conducted for us by Messrs. Stafford, Allen \& Sons, of London, to whom our thanks are due.

A portion of the entire seed, when ground and extracted in a Soxhlet, apparatus with light petroleum (b. p. $30-45^{\circ}$ ), yielded 343 per cent. of fatty oil.

\section{Examination of the Expressed Oil.}

The expressed oil of pumpkin seed, as obtained by us, when viewed in layers of moderate thickness, has a cherry-red color, and possesses a marked fluorescence, whereas in thin layers it appears greenish yellow. It is optically inactive. The constants of the oil were determined with the following results:

1 "Chemical Technology and Analysis of Oils, Fats and Waxes," 3rd Edit., Vol. II, p. 509. 


\begin{tabular}{|c|c|c|}
\hline & Ixpressed oil. & $\begin{array}{l}\text { Oil extracted } \\
\text { by petroleum. }\end{array}$ \\
\hline Specific gravity $20^{\circ} / 20^{\circ}$. & 0.9220 & 0.9212 \\
\hline Acid value $\ldots \ldots \ldots \ldots \ldots \ldots$ & $3 \cdot 4$ & $3 \cdot 5$ \\
\hline Saponification value . . . . . . . & 189.4 & 189.0 \\
\hline Iodine value. ... & 119.7 & $\operatorname{II} 9.6$ \\
\hline
\end{tabular}

For a complete chemical examination of the oil, $25^{\circ}$ grams of it were employed. It was first subjected to distillation with steam. The distillate contained no volatile oil and had only a very slight acid reaction, which appeared to be due to traces of acetic acid.

$$
\text { Hydrolysus of the Oil. }
$$

The oil which had been subjected to distillation with steam, as above described, was separated from the water, the latter then extracted with ether to recover a small amount of stispended oil, and, after adding this to the main portion, the whole was hydrolyzed by heating with an alcoholic solution of 70 grams of potassium hydroxide. The greater portion of the alcohol was then removed, water added, and the alkaline liquid repeatedly extracted with ether. The ethereal liquids were united, washed with a little water, dried with anhydrous sodium sulphate, and the ether removed, when about I gram of a yellow solid was obtained. On fractionally crystallizing the latter from ethyl acetate, the least soluble fraction was obtained in colorless needles, melting at $162-163^{\circ}$. After drying at $I 10^{\circ}$ it was analyzed:

0.0698 gave $0.2139 \mathrm{CO}_{2}$ and $0.0749 \mathrm{H}_{2} \mathrm{O} . \quad \mathrm{C}=83.6 ; \mathrm{H}= \pm 1.9$.

$\mathrm{C}_{27} \mathrm{H}_{48} \mathrm{O}$ requires $\mathrm{C}=83.9 ; \mathrm{H}=1 \mathrm{I} .9$ per cent.

The analysis of this substance, together with the characteristic color reactions yielded by it, establishes its identity as a phytosterol.

The mother liquors from this phytosterol yielded crystalline deposits melting considerably lower than the latter, and the presence of another substance of this class, having an initial melting point of $140^{\circ}$, was indicated. On account of the very small amount of material it was, however, not possible to isolate the more soluble compound in a state of purity.

\section{The Fatly Acids.}

The alkaline, aqueous solution of potassium salts, which had been extracted with ether, as above described, was acidified with sulphuric acid and the liberated fatty acids taken $u p$ by ether. The ethereal solution was washed, dried, and the solvent removed, when 225 grams of total fatty acids were obtained. The constants of the mixed acids ware determined in a portion from which the last traces of ether had been removed by heating for some time at $100^{\circ}$ nnder diminished pressure, and were then as follows: M. p. (complete fusion), $31^{\circ} ; d 50^{\circ} / 50^{\circ}=$ 0.8886 ; neutralization value, I99; iodine value, 123.5 . Optically inactive. A determination of the acetyl value indicated the absence of hy- 
droxy acids. No volatile acids could be detected, either in the total mixture of acids or in the aqueous liquid from which they had been removed by means of ether.

The mixed fatty acids, which consisted of a liquid and a solid portion, were first partially separated by filtration, with the aid of a pump. The solid portion, amounting to 30 grams, was fractionally crystallized from alcohol, and the fractions representing the two extremes of solubility, which melted at $57-58^{\circ}$ and $50-54^{\circ}$, respectively, were analyzed.

Fraction Melting at $57-58^{\circ}$. -0.1290 gave $0.3561 \mathrm{CO}_{2}$ and $0.1463 \mathrm{H}_{2} \mathrm{O} . \quad \mathrm{C}=$ $75 \cdot 3 ; \mathrm{H}=12.6$.

0.1714 gave $0.4727 \mathrm{CO}_{2}$ and $0.196 \mathrm{I}_{2} \mathrm{O} . \quad \mathrm{C}=75.2 ; \mathrm{H}=12.7$.

0.2306 neutralized $8.55 \mathrm{cc}$. $0.1 \mathrm{~N} \mathrm{KOH}$. Neutralization value $=208$.

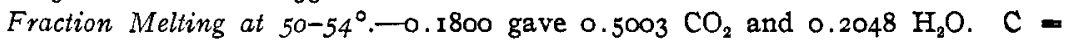
75.8; $\mathrm{H}=12.6$.

$\mathrm{C}_{10} \mathrm{H}_{32} \mathrm{O}_{2}$ requires $\mathrm{C}=75.0 ; \mathrm{H}=12.5$ per cent.

$\mathrm{C}_{18} \mathrm{H}_{36} \mathrm{O}_{2}$ requires $\mathrm{C}=76 . \mathrm{I} ; \mathrm{H}=\mathrm{I} 2.7$ per cent.

These results indicated that both of the above fractions consisted of mixtures of palmitic and stearic acids. As their separation could not be effected by fractional crystallization, this was accomplished by fractionally precipitating a hot alcoholic solution of the acids with concentrated, aqueous barium acetate. Thus the fraction melting at $57-58^{\circ}$ was converted into five fractions of barium salt, which, on treatment with hydrochloric acid, yielded acids melting at $66-67^{\circ}, 64-65^{\circ}, 62-63^{\circ}$,

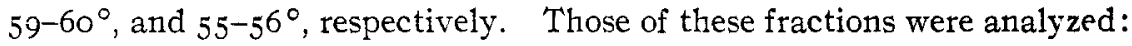

Fraction Melting at $66-67^{\circ} .-0.1247$ gave $0.3474 \mathrm{CO}_{2}$ and $0.1440 \mathrm{H}_{2} \mathrm{O} . \quad \mathrm{C}=$ $76.0 ; \mathrm{H}=12.9$.

$\mathrm{C}_{18} \mathrm{H}_{36} \mathrm{O}_{2}$ requires $\mathrm{C}=76 . \mathrm{r} ; \mathrm{H}=12.7$ per cent.

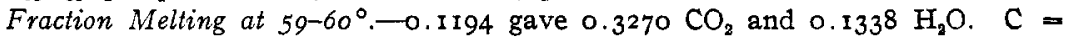
$74.7 ; \mathrm{H}=12.5$.

$\mathrm{C}_{16} \mathrm{H}_{32} \mathrm{O}_{2}$ requires $\mathrm{C}=75.0 ; \mathrm{H}=12.5$ per cent.

Fraction Melting at $55-56^{\circ}$.- - .1030 gave $0.2858 \mathrm{CO}_{2}$ and $0.1159 \mathrm{H}_{2} \mathrm{O}, \mathrm{C}=$ $75.7 ; \mathrm{H}=12.5$.

This fraction was somewhat impure, and the fact that its carbon content is higher than the next preceding one, may be attributed to the presence of a little of the unsaturated acid contained in the oil.

The above results have thus afforded conclusive evidence that the solid acids consisted of a mixture of palmitic and stearic acids, the former predominating. There is, therefore, no indication of the presence of myristic acid, which has been stated ${ }^{1}$ to be a constituent of pumpkin seed oil.

The liquid portion of the total fatty acids was neutralized with an alcoholic solution of potassium hydroxide, and subsequently an alcoholic solution of lead acetate added. The precipitated lead salt was thoroughly washed with water by decantation, and then digested with ether

${ }^{1}$ Loc. cit, 
on a water bath. The ethereal solution, containing the lead saits of the unsaturated acids, was treated with dilute hydrochloric acid, filtered from the lead chloride, washed with water, and the ether removed. The unsaturated acids thus obtained from 250 grams of the fatty oil amounted to 40 grams, and possessed the following constants: B. p. $225-230^{\circ} / 12$ mm.; $d 20^{\circ} / 20^{\circ}=0.9009$; acid value 195.3 ; iodine value 144.3 . The product was analyzed with the following result:

0.1354 gave $0.3807 \mathrm{CO}_{2}$ and $0.1416 \mathrm{H}_{2} \mathrm{O} . \quad \mathrm{C}=76.7 ; \mathrm{H}=11.6$.

$\mathrm{C}_{18} \mathrm{H}_{34} \mathrm{O}_{2}$ requires $\mathrm{C}=76.6 ; \mathrm{H}=2 \mathrm{I} . \mathrm{I}$ per cent. Iodine value $=90 . \mathrm{I}$.

$\mathrm{C}_{18} \mathrm{H}_{32} \mathrm{O}_{2}$ requires $\mathrm{C}=77 . \mathrm{I} ; \mathrm{H}=\mathrm{II} .4$ per cent. Iodine value $=I 8 \mathrm{I} .4$.

It was evident from these results that the unsaturated acids also consisted of a mixture, and, in order to ascertain more definitely the nature of their constituents, a portion ( 36 grams) was oxidized, in alkaline solution, with an equal amount of potassium permanganate. A one per cent. solution of the latter was added gradually at the ordinary temperature, with constant stirring, and at the end of the operation sulphur dioxide was passed into the mixture until all the manganese oxide had dissolved. A pure white precipitate was thus obtained, which was separated by filtration, and digested with large quantities of ether at the ordinary temperature. The ethereal solution, after the removal of the solvent, yielded a product which, when crystallized from alcohol, separated in pearly leaflets, melting at $129-130^{\circ}$ :

o. I240 gave $0.3093 \mathrm{CO}_{2}$ and $0.1276 \mathrm{H}_{2} \mathrm{O} . \quad \mathrm{C}=68.0 ; \mathrm{H}=\mathrm{II} .4$.

$\mathrm{C}_{18} \mathrm{H}_{36} \mathrm{O}_{4}$ requires $\mathrm{C}=68.4 ; \mathrm{H}=\mathrm{II} .4$ per cent.

This product was evidently dihydroxystearic acid, and its formation proved the presence of oleic acid in the oil.

The portion of the oxidation product remaining undissolved by the above-described treatment with ether was repeatedly boiled with large quantities of water and the liquids filtered. The filtrates yielded crystalline deposits melting at about $155^{\circ}$. On recrystallizing these from alcohol, small leaflets were obtained which melted at $157-159^{\circ}$, and this melting point was not raised by fractional crystallization from either alcohol or acetic acid:

$0 . \mathrm{I}_{470} \mathrm{O}$ gave $0.33 \mathrm{I}_{4} \mathrm{CO}_{2}$ and $0 . \mathrm{I}_{3} 65 \mathrm{H}_{2} \mathrm{O} . \quad \mathrm{C}=6 \mathrm{I} .5 ; \mathrm{H}=10.3$.

$\mathrm{C}_{18} \mathrm{H}_{36} \mathrm{O}_{6}$ requires $\mathrm{C}=62 . \mathrm{I} ; \mathrm{H}=10.3$ per cent.

This substance is evidently a tetrahydroxystearic acid (sativic acid), although its melting point is lower than that usually assigned to the latter, namely $173^{\circ}$. It has been noted, however, by several observers that products agreeing in composition and character with tetrahydroxystearic acid possessed melting points varying from $15^{2}$ to $165^{\circ}$, and it is therefore possible that these represent isomeric acids of the formula $\mathrm{C}_{18} \mathrm{H}_{30} \mathrm{O}_{0} \cdot{ }^{1}$

${ }^{1}$ Compare Lewkowitsch, "Chemical Technology and Analysis of Oils, Fats, and Waxes," 2nd Edit., Vol. I, p. 126, and J. Chem. Soc., 87, 899 (1905). 
The isolation of tetrahydroxystearic acid as one of the products of oxidation of the unsaturated acids of pumpkin seed oil is evidence of the presence in the latter of linoleic acid. As no hexahydroxystearic acid (linusic acid) could be isolated from the products of oxidation, it may be concluded that linolenic acid is not a constituent of the oil.

The portion of the precipitated lead salt which remained undissolved by the above-described treatment with ether was examined as follows: The acid was recovered and dissolved in alcohol, when by the addition of successive portions of barium acetate five fractions of barium salt were obtained. The corresponding fractions of acid from these salts melted at the following temperatures: (I) $53-54^{\circ}$; (II) $53-54^{\circ}$; (III) $53^{-54^{\circ}}$; (IV) $54-56^{\circ}$; (V) oily. After recrystallization, the melting points were as follows: (I) $56-58^{\circ}$; (II) $55-56^{\circ}$; (III) $54-55^{\circ}$; (IV) $57-$ $59^{\circ}$. The acid values of these fractions corresponded to the following molecular weights: (I) 270; (II) 265; (III) 264; (IV) 260. The molecular weights of palmitic and stearic acids are 256 and 284 respectively. It was thus ascertained that the solid acids contained in that portion of the precipitated lead salt which was not dissolved by ether were the same as those initially separated from the total fatty acids, and consisted of a mixture of palmitic and stearic acids.

\section{Examination of the Press-cake.}

The so-called "press-cake," resulting from the expression of 22.5 kilograms of pumpkin seeds, deprived as completely as possible of the shells, amounted, as previously noted, to 12.7 kilograms. This material was completely extracted with hot alcohol, when, after the removal of the greater portion of the alcohol, a thin, dark-colored, oily extract was obtained, amounting to 2565 grams. The extract was brought into a flask with water and subjected to distillation with steam, but yielded no volatile product. The contents of the distillation flask separated, on cooling, into an upper layer of fatty oil $(A)$ and a lower aqueous liquid $(B)$, the latter containing some resin $(C)$.

\section{The Fatty Oil $(A)$.}

After separating the fatty oil as completely as possible from the aqueous liquid, the latter was extracted with light petroleum to remove a small amount of suspended oil. The petroleum liquids were then added to the main portion of oil, the whole filtered to remove suspended resin, washed with a little water, dried, and the petroleum removed. A quantity (I 950 grams) of a dark green, fatty oil was thus obtained, which possessed the following constants: $d 20^{\circ} / 20^{\circ}=0.9230$; saponification value, 193.4; iodine value, II5.4. These figures are observed to be in close agreement with those afforded by the expressed oil, the complete investigation of which has already been described. It was therefore evident 
that this product from the press-cake merely represented that portion of the fatty oil of pumpkin seed which had not been removed by expression.

\section{The Aqueous Liquid (B).}

As the resin $(C)$ contained in the aqueous liquid $(B)$ was in too fine a state of division to admit of its separation by filtration, this was effected by decantation, and it was subsequently well washed with water in the same manner. The aqueous liquid $(B)$ then possessed a dark brown color, and when heated with a solution of sodium hydroxide developed ammonia. It yielded a precipitate with mercuric-potassium iodide and with iodine solution, but this behavior was evidently due to protein compounds and not to the presence of an alkaloid, since a preliminary test of the powdered seed for substances of this class by means of Prollius' fluid had given a perfectly negative result.

\section{Isolation of Salicylic Acid.}

The aqueous liquid was repeatedly extracted with ether, the ethereal liquid being washed, dried, and the solvent removed. About I gram of a brown, viscid mass was thus obtained, which gave, with ferric chloride a deep violet coloration. In order to purify the product it was warmed with aqueous sodium carbonate and animal charcoal, but the filtered liquid, on acidification, yielded a precipitate which could not be directly crystallized. On digesting the latter, however, with a large volume of light petroleum, filtering from the resinous matter, and removing the solvent, a very small quantity of colorless needles was obtained, which melted at $150-153^{\circ}$. The substance was soluble in sodium carbonate with evolution of carbon dioxide, gave a violet coloration with ferric chloride, and when heated with methyl alcohol in the presence of sulphuric acid developed the characteristic odor of methyl salicylate. A1though the amount of this substance was not sufficient for an analysis, its identity as salicylic acid could be considered definitely established.

\section{Treatment with Busic Lead Acetate.}

The aqueous liquid, after extraction with ether as above described, was treated with basic lead acetate, which produced a voluminous, yellowish brown precipitate. This was collected on a filter, thoroughly washed with water, then suspended in water, and decomposed by hydrogen sulphide. On filtering the mixture a yellowish red liquid was obtained, which gave only a slight brown coloration with ferric chloride. The liquid was concentrated under diminished pressure, and, as it gave nothing crystalline on standing, was finally mixed with purified sawdust, and the dried mixture successively extracted in a Soxhlet apparatus with ether, ethyl acetate, and alcohol. These solvents, however, did not effect the separation of any crystalline substance. 
The filtrate from the basic lead acetate precipitate was treated with hydrogen sulphide for the removal of the excess of lead, filtered, and this filtrate concentrated under diminished pressure. A reddish brown sirupy liquid was thus obtained, which contained a large amount of sugar, since it readily yielded $d$-phenylglucosazone, melting at 2 I $5^{\circ}$. The liquid deposited nothing crystalline, even on long standing, and a portion, when dried in purified sawdust and extracted successively with ether, ethyl acetate, and alcohol, likewise yielded nothing of a crystalline nature.

\section{Treatment of the Purified Aqueous Liquid with Dilute Sulphuric Acid.}

A portion of the aqueous liquid which had been purified by treatment with basic lead acetate, as above described, was heated for some time in a reflux apparatus with such an amount of sulphuric acid that the latter represented about 5 per cent. by weight of the mixture. On subsequently passing steam through the liquid, the distillate was found to contain formic and acetic acids, but no oily drops. The aqueous, acid liquid remaining in the distillation flask contained a comparatively large quantity of resin. This was collected and well washed with water, but it was quite insoluble in the usual organic solvents, and possessed no further interest. After the separation of the resin, the aqueous liquid, which had a dark brown color, was extracted many times with ether. The combined ethereal liquids were washed, dried, and the solvent removed, when about 3 grams of a yellowish brown oil were obtained, which was fractionally distilled under the ordinary pressure. A small fraction was collected at $100-120^{\circ}$, which contained formic and acetic acids, but the larger portion distilled between 230 and $240^{\circ}$. On redistilling the latter, it passed over between 240 and $260^{\circ}$. This oil possessed a light yellow color, was freely soluble in water, and gave a precipitate with phenylhydrazine acetate. It was, furthermore, soluble in sodium carbonate with evolution of carbon dioxide and yielded a crystalline silver salt. The latter was precipitated in two fractions by the successive addition of silver nitrate to a solution of the sodium salt, and these fractions, after drying in a vacuum over sulphuric acid, were analyzed:

I. 0.0973 of salt gave on ignition, $0.0462 \mathrm{Ag} . \quad \mathrm{Ag}=47.5$.

II. 0.5404 of salt gave on ignition, $0.2628 \mathrm{Ag}$. $\mathrm{Ag}=48.6$.

$\mathrm{C}_{5} \mathrm{H}_{7} \mathrm{O}_{3} \mathrm{Ag}$ requires $\mathrm{Ag}=48.4$ per cent.

These results established the identity of the above-described substance as levulinic acid. Its formation may be attributed to the action of the sulphuric acid on the sugar contained in the aqueous liquid.

The aqueous liquid from which the levulinic acid had been extracted was next treated with just sufficient baryta to remove the sulphuric 
acid, then filtered, and the filtrate concentrated. A dark brown sirup was thus obtained, which deposited nothing crystalline on standing.

It will be seen from the above results that the purified aqueous liquid, on heating with sulphuric acid, yielded no product which would indicate the presence in it of a glucoside.

\section{The Resin (C).}

The resinous material from the "press-cake" amounted to I lo grams, and to this was added a small quantity (ro grams) of resin obtained from the shells of the seed. For the examination of this resinous material it was digested with hot alcohol, then mixed with purified sawdust, and the thoroughly dried mixture extracted successively in a Soxhlet apparatus with various solvents, when the following amounts of extract, dried at $100^{\circ}$, were obtained:

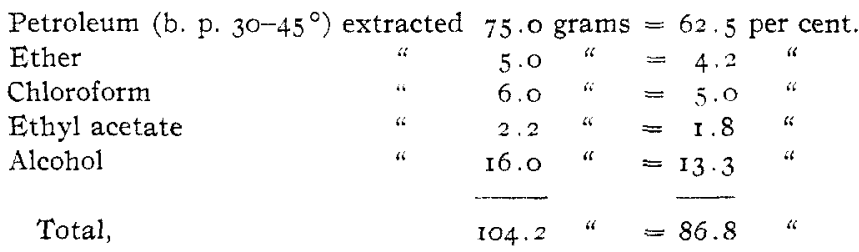

By this process of extraction a portion of the resin had evidently been rendered insoluble.

Petroleum Extract of the Resin.

This was a soft, black mass. It was heated in a reflux apparatus with an excess of an alcoholic solution of potassium hydroxide, the greater portion of the alcohol then removed, water added, and the alkaline mixture extracted with ether. The ethereal liquids were washed, dried, and the solvent removed, when about I gram of a light yellow solid was obtained. This was crystallized a few times from a mixture of ethyl acetate and alcohol, when it finally separated in thin plates, melting at $157-159^{\circ}$. It was a phytosterol, and apparently identical with that previously isolated from the expressed oil of the seed.

Isolation of a New Monocarboxylic Acid, $\mathrm{C}_{25} \mathrm{H}_{51} \mathrm{O} . \mathrm{CO}_{2} \mathrm{H}$.

The alkaline, aqueous liquid, from which the above-mentioned phytosterol had been separated, contained an insoluble potassium salt in suspension. This was removed by filtration and separately examined. For this purpose it was heated for some time with dilute sulphuric acid in the presence of chloroform, when a solution of the corresponding free acid in chloroform was obtained. This solution was washed, dried, and the solvent removed, when it yielded about 0.5 gram of a solid, wax-like substance. The latter was twice crystallized from alcohol, when it melted at $99^{\circ}$. 
0.0986 gave $0.2728 \mathrm{CO}_{2}$ and $0.1138 \mathrm{H}_{2} \mathrm{O}, \mathrm{C}=75.5 ; \mathrm{H}=\mathrm{I} 2.8$.

0.0777 neutralized I. $65 \mathrm{cc}$. O.I $N \mathrm{KOH}$. Neutralization value $=$ IIg. I.

$\mathrm{C}_{26} \mathrm{H}_{32} \mathrm{O}_{3}$ requires $\mathrm{C}=75.7 ; \mathrm{H}=12.6$ per cent. Neutralization value $=136 . \mathrm{I}$.

The composition of this substance would thus appear to be represented by the formula $\mathrm{C}_{26} \mathrm{H}_{52} \mathrm{O}_{3}$, which is that of a hydroxycerotic acid. Two hydroxycerotic acids have hitherto been recorded, one of which was obtained synthetically and is stated to melt at $86.5^{\circ}, 1$ while the other, calculated for the formula $\mathrm{C}_{27} \mathrm{H}_{54} \mathrm{O}_{3}$, was isolated from coca leaves, and is stated to melt at $82^{\circ} .{ }^{2}$ As the above-described acid melts at a considerably higher temperature than either of the acids noted, it is apparently identical with neither of them, and may possibly represent one of the numerous isomerides.

The acid, $\mathrm{C}_{26} \mathrm{H}_{52} \mathrm{O}_{3}$, is very sparingly soluble in light petroleum and in cold alcohol, but is moderately soluble in hot alcohol, and dissolves more readily in ethyl acetate. When heated with ethyl alcohol in the presence of concentrated sulphuric acid, it yielded an ethyl ester, which melted at $6 \mathrm{I}^{\circ}$. An attempt to obtain an acetyl derivative of the acid was not successful.

The alkaline, aqueous liquid from which the insoluble potassium salt had been removed, as above described, was acidified with sulphuric acid and distilled with steam, but no volatile acid was found in the distillate. The contents of the distillation flask were then extracted with ether, the ethereal liquid being filtered to remove some suspended resin, washed, dried, and the solvent removed. A quantity of dark colored, solid fatty acid was thus obtained which, when distilled under diminished pressure, passed over almost entirely between 228 and $233 \%$ I 5 $\mathrm{mm}$., only a small amount of non-volatile resin remaining behind. The distillate was crystallized from acetic acid, when a product was obtained which melted at $54^{\circ}$.

0.2224 neutralized $8.05 \mathrm{cc}$. $0.1 \mathrm{~N} \mathrm{KOH}$. Neutralization value $=203 . \mathrm{I}$.

$\mathrm{C}_{16} \mathrm{H}_{32} \mathrm{O}_{2}$ requires a neutralization value of $219 . \mathrm{I}$.

$\mathrm{C}_{18} \mathrm{H}_{36} \mathrm{O}_{2}$ requires a neutralization value of $197 \cdot 5$.

This product evidently consisted of a mixture of palmitic and stearic acids.

The mother-liquors remaining from the crystallization of the above product were found to contain some unsaturated acid. The acids contained in the mixture were therefore evidently the same as those previously identified by us in the expressed oil of pumpkin seed.

Ether Extract of the Resin.

This was a black, soft solid, amounting to only 5 grams. It was redissolved in ether, the ethereal solution being then extracted with aqueous

1 Ann. chim. phys. [7], 7, 227.

2 Ann., 27x, 222 (1892). 
sodium carbonate, and subsequently with a 10 per cent. solution of sodium hydroxide. The sodium carbonate extract had a dark brown color and contained some insoluble sodium salt in suspension. The whole was acidified with dilute sulphuric acict, and extracted with ether, the ethereal liquid being washed, dried, and the solvent removed. A dark brown solid was thus obtained, which was dissolved in alcohol, and the solution decolorized by animal charcoal. On concentrating the liquid a very small amount of a colorless substance was deposited, which melted at 98-99 and was identical with the acid $\mathrm{C}_{56} \mathrm{~F}_{52} \mathrm{O}_{3}$. which had previously been isolated from the petroleum extract of the resin. The subsequent extraction of the original ethereal solution with sodium hydroxide yielded only a trace of an amorphous, yellow solid, and on finally removing the ether only a small quantity of a light green, gelatinous mass was obtained.

Chloroform, Ethyl Acetate and Alcohol Extracts of the Resin.

These were all black, brittle solids, and nothing crystalline could be obtained trom them.

\section{Examination of the Shells.}

The shells or husks from 22.5 kilograms of pumpkin seed amounted to 4680 grams, thus corresponding to 20.8 per cent. of the weight of the latter.

The material was ground and extracted by continuous percolation with hot alcohol. After the removal of the greater portion of the alcohol there remained a dark-colored oil. This was mixed with water and distilled with steam, but no volatile product was obtained. The contents of the distillation flask separated, on cooling, into an upper layer of fatty oil $(A)$ and a lower aqueous liquid $(B)$, the latter containing some resin $(C)$.

\section{The Fatty Oil $(A)$.}

The entire liquid contained in the distillation flask, consisting, as above described, of fatty oil and a lower aqueous portion, was shaken with light petroleum. The petroleum liquid was filtered to remove a small amount of resin, washed with water, dried with anhydrous sodium sulphate, and the solvent removed. A quantity (595 grams) of a dark green, fatty oil was thus obtained, which possessed the following constants: $d 20^{\circ} / 20^{\circ}=0.9236$; saponification value, 190.3 ; iodine value, II 8.5 . These figures are in close agreement with those afforded by both the expressed oil and that obtained from the "press-cake," and the constituents of the three oils were practically the same.

The Aqueous Liquid (B).

This liquid, which had a dark brown color, was filtered to remove a small amount of resin. It was then repeatedly extracted with ether, 
the combined ethereal liquids being washed, dried, and the solvent removed, when about 2 grams of a dark brown, resinous substance were obtained. The latter was redissolved in ether, and the ethereal solution extracted with alkalies, which removed the greater portion of the substance. It gave a violet coloration with ferric chloride and appeared to contain traces of salicylic acid, which had been definitely identified in a corresponding product from the "press-cake," but the amount in the present instance was too small to permit of its isolation.

The aqueous liquid was subsequently treated with a slight excess of basic lead acetate, which produced a voluminous, light brown precipitate. The latter was collected on a filter, well washed, and then suspended in water and decomposed by hydrogen sulphide. After removing the lead sulphide by filtration, a reddish brown liquid was obtained, which gave a dark brown coloration with ferric chloride, indicating the presence of some tannic matter. This liquid was concentrated under diminished pressure, but nothing separated on standing, and, when mixed with purified sawdust, and the dried mixture extracted with various solvents, it yielded nothing crystalline.

The filtrate and washings from the basic lead acetate precipitate possessed a light green color. This was due to the presence of a very small amount of copper, which, by a special test, was found to be contained in the original pumpkin seed. ${ }^{1}$ After treatment with hydrogen sulphide for the removal of the excess of lead, and filtering, the liquid was concentrated under diminished pressure to a small bulk. It then had a reddish brown color and contained a quantity of sugar, since it readily yielded $d$-phenylglueosazone, melting at $208^{\circ}$. A portion of the liquid was mixed with purified sawdust and the dried mixture extracted successively with ether, ethyl acetate, and alcohol, but no crystalline substance was removed by these solvents. Another portion of the liquid was treated with dilute sulphuric acid in the manner described in connection with the corresponding. liquid from the "press-cake." The products were the same as those yielded by the last-mentioned liquid.

\section{The Resin (C).}

The total amount of resinous material obtained from the shells of the pumpkin seed was about Io grams. It formed a black, brittle mass, and, as already noted, was examined in connection with the larger amount of resin obtained from the "press-cake."

\section{Summary and Conclusions.}

In view of the somewhat extended details of the present investigation, a summary of the more important results may here be appended,

${ }^{1}$ An account of the wide distribution of copper, in both the vegetable and animal kingdoms, is recorded in the Am. J. Pharm., 77, 274 (1905). 
together with a record of some physiological tests and the deductions therefrom.

The kernels of the pumpkin seed, separated as completely as possible from the shells, were subjected in strong hydraulic pressure, when they yielded a quantity of fatty oil, together with the so-called "press-cake." These products were then separately examined.

I. The Fatty On.--The amount of oil obtained from the kernels by expression corresponded to 19.3 per cent. of the weight of the entire seed. The entire seed, when ground and extracted with light petroleum, yielded 34.3 per cent. of fatty oil. The expressed oil, which was optically inactive, possessed the following constants: Specific gravity, $20^{\circ} / 20^{\circ}=$ 0.9220 ; acid value, 3.4 ; saponification value, 189.4 ; iodine value, II 9.7 . The composition of the oil was approximately as follows:

Linoleic acid, as glyceride, Oleic acid, as glyceride, Palmitic acid ?

$\left.\begin{array}{l}\text { Palmitic acid } \\ \text { Stearic acid }\end{array}\right\}$ as glycerides, 30
45 per cent.

25

100

The oil contains no myristic acid, as has previously been asserted, and of the two solid acids the palmitic acid is in somewhat the larger amount. It contains a very small amount of a phytosterol, $\mathrm{C}_{37} \mathrm{H}_{46} \mathrm{O}$ (m. p. $I 62-I 63^{\circ}$, and apparently another substance of this class, having a lower melting point.

II. The "Press-cake."-This material was extracted with hot alcohol, and in the resulting product the presence of the following constituents was determined: (I) A quantity of fatty oil, corresponding to 8.7 per cent. of the weight of the entire seed, and agreeing closely in character with that obtained by expression; (2) soluble protein products; (3) a quantity of sugar; (4) a very small amount of salicylic acid; (5) resinous material, amounting to about 0.5 per cent. of the weight of the entire seed. From the resin there were isolated a very small amount of a phy-

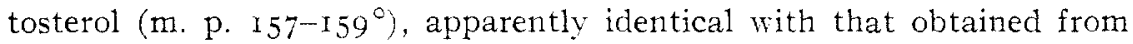
the expressed oil, and a new monocarboxylic acid (m. 1).99 ${ }^{\circ}$ ), agreeing in composition with a hydroxycerotic acid, $\mathrm{C}_{25} \mathrm{H}_{51} \mathrm{O} . \mathrm{CO}_{2} \mathrm{H}$, which yielded an ethyl ester melting at $61^{\circ}$.

III. The Shells.--These amounted to 20.8 per cent. of the weight of the entire seed. When extracted with hot alcohol they yielded a fatty oil (amounting to 2.6 per cent. of the weight of the entire seed), which agreed closely in character with that obtained from the kemels by expression. They also contained sugar and a very small amount of resinous material. With the exception of traces of copper, a complete examination of the shells disclosed the presence of no substance which is not contained in the kernel of the seed. 
Physiological Tests.

It was finally deemed of interest to ascertain, if possible, whether either the fatty oil or the resin possesses the taenifuge properties which are ascribed to pumpkin seed. For this purpose some preliminary experiments were kindly conducted for us by Dr. H. H. Dale, Director of the Wellcome Physiological Research Laboratories, to whom our thanks are due.

The pure expressed oil of pumpkin seed, such as was used for our chemical investigation, was administered in doses of $30 \mathrm{cc}$, and under the usual conditions of a restricted diet, to two dogs that were known to be afflicted with tapeworm. After an interval of several hours, castor oil was given, but in neither of these cases could any tapeworm be found in the excreta.

One gram of the resin, obtained from the kernel of the seed as above described, was administered to a small dog which had been given no food for 20 hours. Nothing happened during the 6 hours following its administration, and the dog was then given $20 \mathrm{cc}$. of castor oil. This produced fairly copious, loose evacuations, in which isolated, macerated proglottides were detected, but no considerable length of tapeworm. The resin obtained from the shells or husks of the seed was given to another dog in about the same amount ( 0.9 gram) as in the preceding experiment, and under similar conditions, but with an equally negative result. While these experiments have thus shown the resin of pumpkin seed to be perfectly innocuous, they have, on the other hand, afforded no indication that it possesses anthelmintic properties.

Through the kindness of several medical practitioners in different parts of the country an opportunity was afforded us of testing the pumpkin seed oil in five cases of tapeworm, four of which occurred in children. The amount of oil administered varied from half a fluidounce to two ounces ( 15 to $60 \mathrm{cc}$.), and, although the dose was in some cases repeated, in no instance did it effect the complete removal of the worm. In one of these cases, that of a child of seven years, in which 2 ounces $(60 \mathrm{cc}$.) of the oil had removed a portion of the worm, a trial was subsequently made of the resin from the seed. One gram of this material (representing approximately 200 grams of pumpkin seed) was administered in the early morning, while fasting, and was followed in two hours by a dose of castor oil. No ill effects were observed, and, although the child was purged several times, neither the worm nor any fragment of it appeared.

In conclusion it may be said that the results of the above-described experiments do not enable us to confirm the recorded statements respecting the efficacy of either the fatty oil or the resin of pumpkin seed as a taenifuge. As it is evident that these seeds contain no principle exhibiting marked physiological activity, any value which they may actually 
possess, when administered in substance for the purpose indicated, would therefore appear to be attributable to a mechanical action. In any case, the remedial value of pumpkin seeds cannot be considered such as to justify their recognition by a national pharmacopoeia.

[CONTRIbution from the Welicome Chemical Research Laboratories, London.] CHEMICAL EXAMINATION OF WATERMELON SEED.

BY FREDERICK B. POWFR aNd ARTHER f. SALTAY. Received January I3, rgio.

The seeds of the watermelon ( $C$ ucurbita citrullus, Linné) have been employed to some extent medicinally on account of their diuretic properties, but chiefly as a domestic remedy. So far as known to us, they have never been examined chemically. Lewkowitsch ${ }^{1}$ has briefly noted the physical and chemical constants of the fatty oil, and of the mixed fatty acids obtained therefrom, but makes no statement regarding the composition of the oil, and no further information concerning this product appears to be available.

As many of the plants belonging to the family of Cucurbitaceae contain in some of their parts substances which possess a considerable degree of physiological activity, it was deemed desirable to submit the seeds of the watermelon to a complete chemical examination. Such an investigation appeared, furthermore, of interest from the point of view of comparing the constituents of these seeds with those of the common pumpkin (Cucurbita pepo, Linne), which have recently been completely examined by us. ${ }^{2}$

\section{EXPERIMENTAL.}

The material employed was obtained from the United States and consisted of fresh watermelon seeds of good quality.

A portion of the crushed seed was first tested for the presence of an alkaloid by means of Prollius' fluid, but with a negative result.

For the purpose of a complete investigation, 22.5 kilograms of the seed were crushed and the shells separated as completely as possible from the kernels. The shells amounted to 10.95 kilograms, thus corresponding to 48.7 per cent. of the weight of the seed. The ground kernels were then subjected to strong hydraulic pressure, when $166_{5}$ grams of fatty oil were obtained, corresponding to 7.4 per cent. of the weight of the entire seed. The so-called "press-cake" remaining after the removal of the oil amounted to 8.88 kilograms. These operations, connected with the expression of the oil, were carefully conducted for us by Messrs. Stafford, Allen \& Sons, of London, to whom our thanks are due.

1 "Chemical Technology and Analysis of Oils, Fats and Waxes," 3 rd Edit., Vol II, p. 5 II.

: This Journai, 32, 346 . 